\title{
Gastrointestinal Bleeding Scintigraphy in the Early 21st Century
}

\author{
Erin Grady ${ }^{1}$ \\ ${ }^{1}$ Section of Nuclear Medicine, Department of Radiology, Christiana Care Health System, Newark, Delaware
}

\begin{abstract}
Learning Objectives: On successful completion of this activity, participants should be able to describe (1) diagnostic uses of gastrointestinal bleeding scintigraphy; (2) proper methodology for performing the procedure; (3) the importance of correlative and hybrid imaging; (4) interpretive criteria to make a clinical diagnosis; (5) special considerations in children; and (6) imaging of Meckel diverticula.
\end{abstract}

Financial Disclosure: The author of this article has indicated no relevant relationships that could be perceived as a real or apparent conflict of interest.

CME Credit: SNMMI is accredited by the Accreditation Council for Continuing Medical Education (ACCME) to sponsor continuing education for physicians. SNMMI designates each JNM continuing education article for a maximum of 2.0 AMA PRA Category 1 Credits. Physicians should claim only credit commensurate with the extent of their participation in the activity. For CE credit, SAM, and other credit types, participants can access this activity through the SNMMI website (http://www.snmmilearningcenter.org) through February 2019.

Gastrointestinal bleeding scintigraphy performed with 99mTclabeled autologous erythrocytes or historically with $99 \mathrm{mTc}$-sulfur colloid has been a clinically useful tool since the 1970s. This article reviews the history of the techniques, the different methods of radiolabeling erythrocytes, the procedure, useful indications, diagnostic accuracy, the use of SPECT/CT and CT angiography to evaluate gastrointestinal bleeding, and Meckel diverticulum imaging. The causes of pediatric bleeding are discussed by age.

Key Words: Gl bleeding scintigraphy or scan; radiolabeled red blood cells or erythrocytes; SPECT; SPECT/CT; CTA; pediatric GI bleeding by age; Meckel's diverticulum

J Nucl Med 2016; 57:252-259

DOI: 10.2967/jnumed.115.157289

$\mathbf{I}$ was in 1977 that Alavi et al., at the University of Pennsylvania, originally described evaluating gastrointestinal bleeding with scintigraphic methods using ${ }^{99} \mathrm{~m}$ Tc-sulfur colloid (1). Also in 1977, at the University of Copenhagen, Miskowiak et al. described the use of 99mTc-human serum albumin for gastrointestinal bleeding (2). Subsequently, in 1979 at the Massachusetts General Hospital, Winzelberg et al. described diagnosing and localizing gastrointestinal bleeding with ${ }^{99 \mathrm{~m} T c-e r y t h r o c y t e s}$ (3). Other techniques for labeling red blood cells with greater efficiency were developed later, but the practice of evaluating gastrointestinal bleeding with scintigraphic techniques had already become established in clinical practice.

Gastrointestinal bleeding is one of the major causes of death in the United States, with mortality ranging from $10 \%$ to $30 \%$ (4). In light of the significant mortality, timely diagnosis and evaluation are critical, as emergent intervention may be needed. Bleeding may originate

Received Nov. 2, 2015; revision accepted Dec. 10, 2015.

For correspondence or reprints contact: Erin Grady, Department of Radiology, Section of Nuclear Medicine, Christiana Care Health System, 4755 Ogletown-Stanton Rd., Newark, DE 19718.

E-mail: egrady@christianacare.org

Published online Dec. 17, 2015.

COPYRIGHT (c) 2016 by the Society of Nuclear Medicine and Molecular Imaging, Inc. from the upper or lower gastrointestinal tract. Upper gastrointestinal bleeding - bleeding originating in any portion of the tract up to the ligament of Treitz at the duodenal flexure-annually affects 50-150 of every 100,000 adults (4) and causes 20,000 deaths in the United States (5). Lower gastrointestinal bleeding originates distal to the ligament of Treitz and is fairly common, accounting for approximately $21 \%$ of gastrointestinal bleeding overall (6) but is usually self-limited. The prevalence of lower gastrointestinal bleeding increases by more than 200 times between the ages of 30 and $90 \mathrm{y}(7)$. Approximately 21 of every 100,000 adults in the United States require hospitalization for lower gastrointestinal bleeding annually (4). Upper and lower gastrointestinal bleeding require different clinical approaches, but although each has its usual signs the source of bleeding can be difficult to distinguish clinically. Upper bleeding generally presents with hematemesis (either red or coffeeground emesis) or melena. Some melena, however, may be related to the ascending colon. Hematochezia is most often due to a lower bleed, but a brisk upper bleed could have a similar appearance. Noninvasive imaging and other tests assist the clinician in determining the appropriate treatment.

Scintigraphy is indicated for evaluation of overt gastrointestinal bleeding. Per the SNMMI guidelines for gastrointestinal bleeding scintigraphy (GIBS), the goal of the examination is to determine whether the patient is actively bleeding, to localize the bleeding bowel segment, and to estimate the rate of blood loss (7). All of these allow for treatment planning and risk stratification (8). GIBS does best in the mid to lower gastrointestinal tract. Occult bleeding identified by guaiac fecal testing is not an appropriate indication: the microscopic blood; slow, intermittent bleeding; or low-volume blood identified in stool is below the scintigraphic detection limit (7).

\section{TECHNIQUE}

Before initiation of scanning, it is important to learn more about the patient and the patient's symptoms. Understanding clinical descriptions of gastrointestinal bleeding such as overt or occult is helpful in elucidating patient history from our clinical colleagues (Table 1) (8). Areas to explore include the clinical signs of gastrointestinal bleeding; the color of the blood; the physical examination results, including rectal examination or nasogastric lavage, if performed; the results of prior imaging, endoscopy, or colonoscopy; whether the 
TABLE 1

Definitions of Various Types of Gastrointestinal Bleeding (8)

\begin{tabular}{ll}
\hline \multicolumn{1}{c}{ Term } & \multicolumn{1}{c}{ Definition } \\
\hline $\begin{array}{l}\text { Overt or acute gastrointestinal bleeding } \\
\text { Occult or chronic gastrointestinal bleeding }\end{array}$ & $\begin{array}{l}\text { Visible bleeding in the form of hematemesis, melena, or hematochezia } \\
\text { Bleeding not apparent to patient and presenting as anemia or on fecal occult } \\
\text { blood testing }\end{array}$ \\
\hline Obscure gastrointestinal bleeding & Recurrent bleeding of uncertain source after or despite upper or lower endoscopy \\
\hline Hematemesis & Vomiting of blood \\
Melena & Dark, tarry/sticky feces containing partially digested blood \\
\hline Hematochezia & Passage of fresh blood per anus, usually in or within stools \\
\hline
\end{tabular}

patient is stable enough to come to the imaging department; and whether a portable scanner is available. Good intravenous access is key; the patient should have 1 or 2 large-bore intravenous lines and fluid resuscitation products available on demand on entry to the nuclear medicine area. It is important to note whether the patient had any prior bowel or abdominal surgery and whether the surgery was recent; patients who recently underwent barium evaluation should be excluded from GIBS as the findings may be obscured (7). Knowing the patient's medications is helpful, especially when troubleshooting the cause of poor erythrocyte labeling. A list of medications and other substances contributing to poor labeling is available in Table 2 (9-15).

${ }^{99 \mathrm{~m}} \mathrm{Tc}$-sulfur colloid has a short circulating half-life of $3 \mathrm{~min}$ and an equally quick extraction by the reticuloendothelial system (liver, spleen, and bone marrow) (11). Imaging is generally performed for 20-30 min with ${ }^{99 \mathrm{~m}} \mathrm{Tc}$-sulfur colloid, decreasing the opportunity to visualize the classically intermittent lower gastrointestinal bleed. The high level of background activity in the liver and spleen can obscure upper-gastrointestinal bleeding sources. For these reasons, multiple studies have found ${ }^{99 \mathrm{~m}} \mathrm{Tc}$-erythrocytes to be superior $(16-18)$. In other countries, ${ }^{99 \mathrm{~m}} \mathrm{Tc}$-human serum albumin diethylenetriaminepentaacetic acid is used for the diagnosis of gastrointestinal bleeding (19). All these radiopharmaceuticals assist in compartmental localization. Each of them images the vascular compart- ment, although some tracers stay in the vascular compartment longer than others.

There are 3 ways to label erythrocytes: in vivo, modified in vivo, and in vitro. In the in vivo method, no blood is withdrawn from the patient. The patient receives an intravenous injection of stannous pyrophosphate, which is allowed to circulate for a few minutes, followed by intravenous injection of ${ }^{99 \mathrm{~m}} \mathrm{Tc}$-pertechnetate. This technique is generally not preferred because it has the lowest labeling efficiency, but it is reserved for patients who will not receive blood products for religious reasons $(11,20)$. The modified in vivo method, also known as the "in vivtro" method, begins similarly to the in vivo method with intravenous injection of stannous pyrophosphate; blood is subsequently withdrawn from the patient and mixed with ${ }^{99 \mathrm{~m}} \mathrm{Tc}-$ pertechnetate. This method has a somewhat higher labeling efficiency $(11,20)$. In the in vitro method, blood is withdrawn from the patient and a cold kit containing stannous pyrophosphate and a few other components is used; ${ }^{99 \mathrm{~m}}$ Tc-pertechnetate is added. This method has the highest labeling efficiency, which improves the target-tobackground ratio and decreases the likelihood that free pertechnetate will interfere with interpretation of the results. Care must be taken to ensure that each patient receives back his or her own radiolabeled blood product.

The erythrocyte labeling techniques are summarized in Table 3. All have one thing in common: use of a redox reaction (Fig. 1) that results

TABLE 2

Causes of Interference with Erythrocyte Radiolabeling, Leading to Free 99mTc-Pertechnetate (9-15)

\begin{tabular}{|c|c|}
\hline Cause & Mechanism of disrupted radiolabeling \\
\hline Methyldopa & Oxidation of stannous ion; decrease in reduction \\
\hline Hydralazine & Oxidation of stannous ion; decrease in reduction \\
\hline Quinine & Possible antibody to red blood cells \\
\hline Doxorubicin & Lowered labeling efficiency in proportion to concentration of drug \\
\hline lodinated contrast medium & Decrease in stannous reduction; alteration of ${ }^{99 m} \mathrm{Tc}$ binding \\
\hline Chocolate & Unknown \\
\hline Tobacco & $\begin{array}{l}\text { Oxidation of stannous ion, possible damage to red blood cell plasma membrane or } \\
\text { possible chelating action on stannous or pertechnetate ions (mechanism relates to } \\
\text { reactive oxygen species present) }\end{array}$ \\
\hline Heparin & $\begin{array}{l}\text { Formation of complexes with } 99 \mathrm{~m} \text { Tc-pertechnetate in presence of stannous ion, } \\
\text { causing renal excretion }\end{array}$ \\
\hline Too much or too little stannous ion & Alteration of $99 \mathrm{~m} T c$-pertechnetate reduction \\
\hline Recent blood transfusion & Unknown \\
\hline Sickled red blood cells & Impaired labeling due to abnormal hemoglobin structure \\
\hline
\end{tabular}


TABLE 3

Methods of Labeling Erythrocytes with 99mTc and Labeling Efficiency $(3,11,20,21)$

\begin{tabular}{|c|c|c|}
\hline Method & Description and considerations & Efficiency \\
\hline In vivo & $\begin{array}{l}\text { Patient is injected intravenously with } 1 \mathrm{mg} \text { of stannous pyrophosphate, which } \\
\text { circulates for } 20 \mathrm{~min} \text {, followed by intravenous injection of } 555-1,110 \mathrm{MBq} \text { of }{ }^{99 \mathrm{~m} T \mathrm{~T}-} \\
\text { pertechnetate. This technique is generally not recommended because of its low } \\
\text { labeling efficiency but is reserved for patients who will not receive blood products } \\
\text { for religious reasons. }\end{array}$ & $75 \%-80 \%$ \\
\hline Modified in vivo & $\begin{array}{l}\text { Patient is injected intravenously with } 1 \mathrm{mg} \text { of stannous pyrophosphate, which } \\
\text { circulates for } 20 \mathrm{~min} \text {. Vial of blood is mixed with } 555-1,110 \mathrm{MBq} \text { of } 99 \mathrm{mTc}- \\
\text { pertechnetate and allowed to incubate for } 10 \mathrm{~min} \text { before intravenous injection into } \\
\text { patient. }\end{array}$ & $85 \%-90 \%$ \\
\hline In vitro & $\begin{array}{l}\text { Vial of blood is withdrawn from patient and added to vial containing stannous } \\
\text { pyrophosphate. After } 5 \mathrm{~min} \text {, vial A containing sodium hypochlorite is added to } \\
\text { destroy extracellular } \mathrm{Sn}^{2+} \text {. Vial B containing citrate buffer is then added. } 99 \mathrm{mTC} \text { - } \\
\text { pertechnetate (555-1,110 } \mathrm{MBq} \text { ) is added and incubated before intravenous } \\
\text { administration to patient. }\end{array}$ & $\geq 97 \%$ \\
\hline
\end{tabular}

in labeling of the erythrocytes at the $\beta$-chain of the hemoglobin (3). In this redox reaction, $\mathrm{Tc}^{7+} \mathrm{O}_{4}{ }^{-}$is the oxidizing agent and the stannous ion $\left(\mathrm{Sn}^{2+}\right)$ is the reducing agent $(11,20,21)$.

After the patient's erythrocytes have been labeled and readministered, a dynamic acquisition of the abdomen and pelvis is performed with a $128^{2}$ matrix. The dynamic images are acquired for 10-20 s/frame, with an optional initial angiographic phase obtained for 1-3 s/frame (7). The dynamic images can be reframed or summed on an as-needed basis to increase the information density per frame. Acquiring static images other than for troubleshooting is not recommended, as cine visualization is key to interpretation (22). If a dual-head $\gamma$-camera is used for evaluation, acquiring the images with both camera heads may enhance visualization of a rectal bleed (7). The scanning duration is not standardized but should be long enough to allow for intermittent bleeding, which is a particular possibility in the large bowel. An imaging interval of 1-4 h, depending on camera availability, is reasonable (7), although some studies indicate that $1-2 \mathrm{~h}$ would be optimal $(23,24)$.

\section{NORMAL BIODISTRIBUTION AND INTERPRETATION}

The normal biodistribution of ${ }^{99 \mathrm{~m}} \mathrm{Tc}$-radiolabeled erythrocytes includes the cardiac blood pool, vasculature, liver, spleen, penile circulation, and usually mildly in the kidneys and urinary bladder (Fig. 2).

The scintigraphic results will be positive only if the patient is actively bleeding at the time of imaging. To diagnose a gastrointestinal

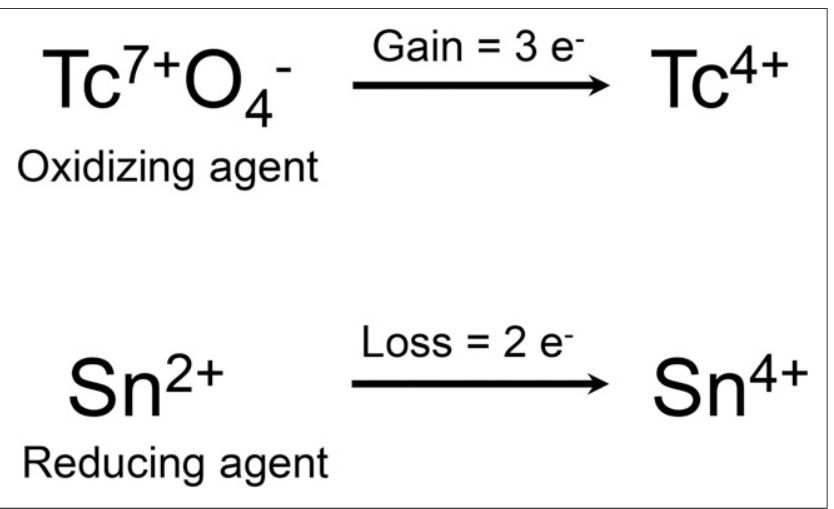

FIGURE 1. Stannous reduction method (3). bleed, 4 criteria need to be met: the focus of extravascular activity should start in a region where there was no abnormal activity before, should increase in intensity over time, should move in either an anterograde or a retrograde fashion, and should conform to the bowel (11). When identifying the site of bleeding, it is important to know the major feeding vessel. The major feeding vessels are determined embryologically: perfusing the foregut, midgut, and hindgut. The portion of the foregut that is visualized on GIBS is the stomach through the second part of the duodenum and is perfused by the celiac trunk; the branches of the celiac trunk include the left gastric artery, common hepatic artery, and splenic artery. The midgut is perfused by the superior mesenteric artery, from the duodenal papilla through most of the transverse colon; the branches of the superior mesenteric artery include the inferior pancreaticoduodenal artery, intestinal arteries, ileocolic artery, right colic artery, and middle colic artery. The hindgut is perfused by the inferior mesenteric artery, from the remaining transverse colon through the superior portion of the anal canal; the branches of the inferior mesenteric

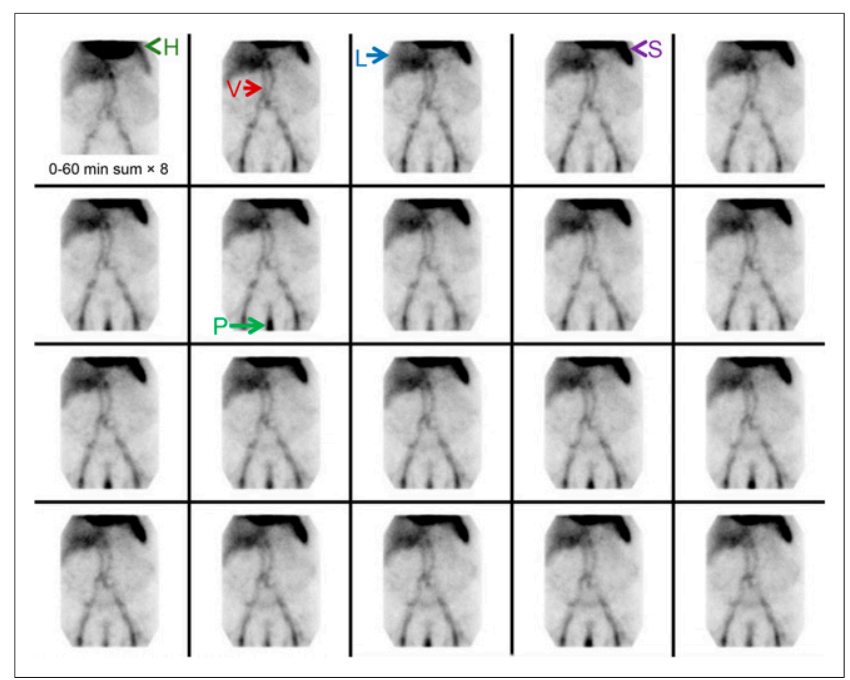

FIGURE 2. Normal biodistribution of $99 \mathrm{mTC}$-labeled erythrocytes. Heart $(\mathrm{H})$, vascular structures $(\mathrm{V})$, liver $(\mathrm{L})$, spleen $(\mathrm{S})$, and penis $(\mathrm{P})$ are labeled. We see no intraluminal activity to suggest presence of active gastrointestinal bleed. 
artery include the left colic artery, sigmoid branches, and superior rectal artery $(11,25)$. Examples of bleeding at these 3 major sites are illustrated in Figures 3-5. Localizing the main arterial distribution is helpful when planning angiographic intervention. Variceal bleeding is also an important finding but does not have an arterial source.

Some institutions perform delayed dynamic imaging, which may not accurately localize the origin of bleeding unless the 4 criteria are met. Blood urea nitrogen and creatinine tests can be helpful, as a blood urea nitrogen-to-creatinine ratio of 25 or greater indicates a greater likelihood of a positive result on delayed imaging (26). Some work has suggested a prognostic benefit to delayed GIBS (27). Digital subtraction has been found helpful in this setting (7).

\section{PITFALLS AND PEARLS}

Several potential false-positive findings can occur in GIBS. Red blood cells can localize at a site other than that of the worrisome gastrointestinal bleeding, such as in the case of splenosis, pancreatic pseudocysts, or nonenteric bleeding/hematoma $(7,8,28)$. Other physiologic activity can occasionally confuse the interpreter; this activity is usually fixed. Previously reported sources of error include renal activity from a morphologically normal kidney, a transplanted or horseshoe kidney, urine in the bladder or urine contamination, a urinary diversion, a dilated abdominal aorta, bowel ischemia, hepatic hemangioma, vascular collaterals such as caput medusa or dilated mesenteric veins, angiodysplasia, the left ovarian artery and gallbladder in patients with renal failure, the penis, the uterus, and a uterine leiomyoma $(7,20)$. If the patient has had recent bowel or other abdominal surgery, prominent activity can be seen related to normal postoperative hyperemia. Inflammatory bowel diseases such as Crohn disease, a diverticular abscess, and hypervascular neoplasms may also make interpretation difficult $(7,20)$.

Relying on all 4 criteria to positively diagnose a gastrointestinal bleed will often clarify whether the patient has active gastrointestinal

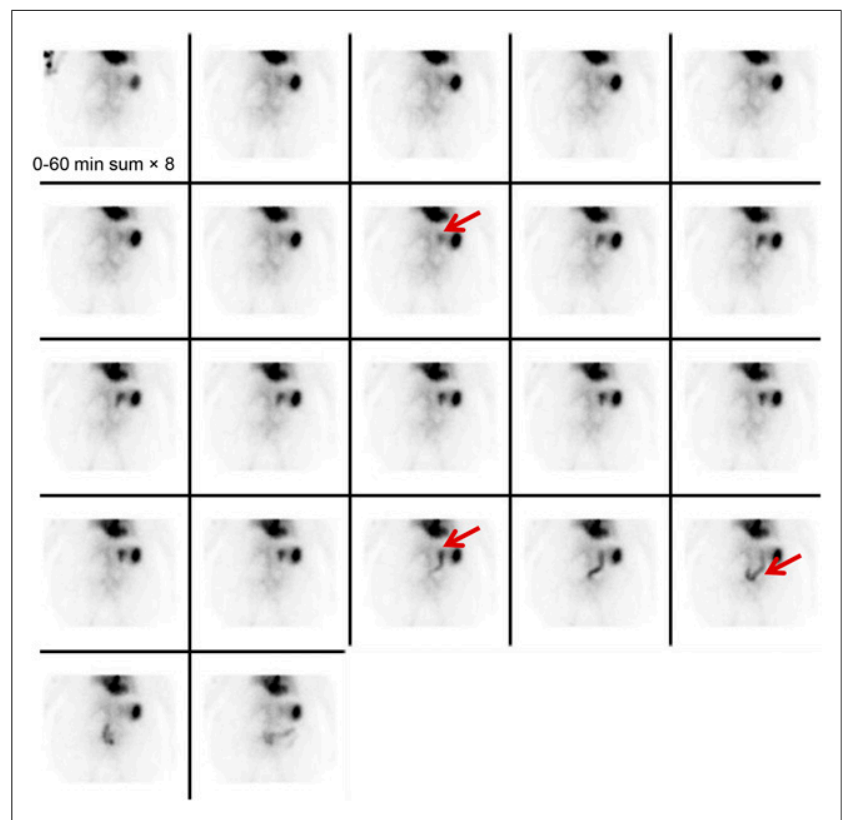

FIGURE 3. Example of bleeding originating from branch of celiac artery. Focus of increasing intensity is identified in upper abdomen, moves in anterograde fashion, and conforms to bowel. Distribution of focus is suggestive of gastric bleed (arrows).

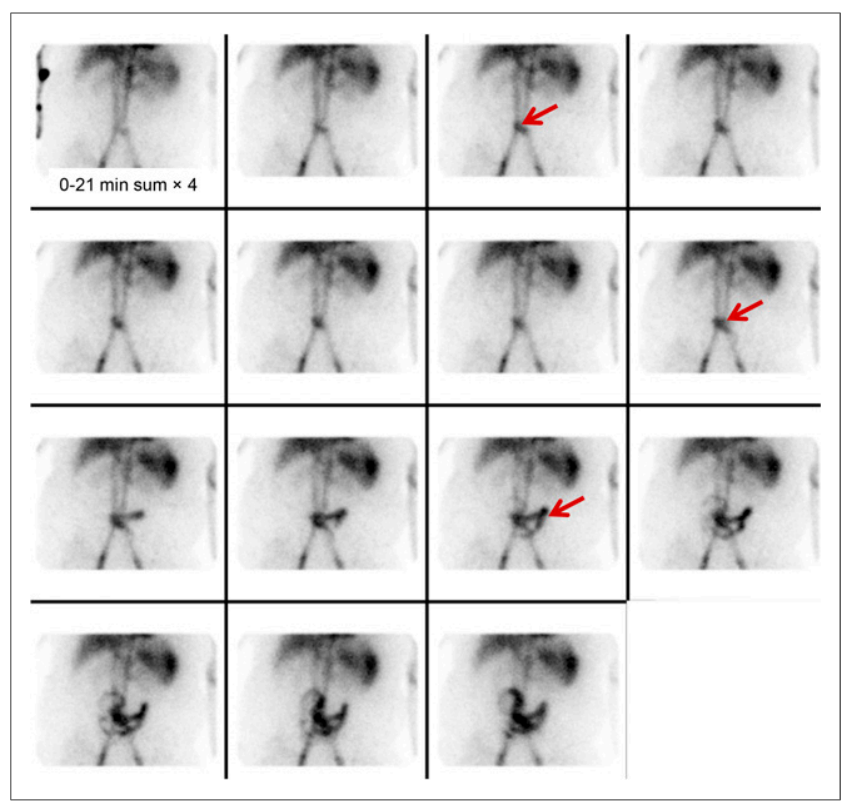

FIGURE 4. Example of bleeding originating from branch of superior mesenteric artery. Focus of increasing intensity is identified in lower abdomen at midline (arrows) and shows anterograde and retrograde movement conforming to bowel lumen. Focus crosses midline several times and thus is most compatible with small-bowel bleed.

bleeding or another process masquerading as bleeding. The true etiology of certain findings may be clarified by performing static imaging in the lateral or oblique projection, SPECT, or SPECT/CT or by correlating the images with a prior CT scan. In particular, static images of the neck with attention to the thyroid and salivary glands are often obtained to exclude the presence of free ${ }^{99 \mathrm{~m}} \mathrm{Tc}$-pertechnetate

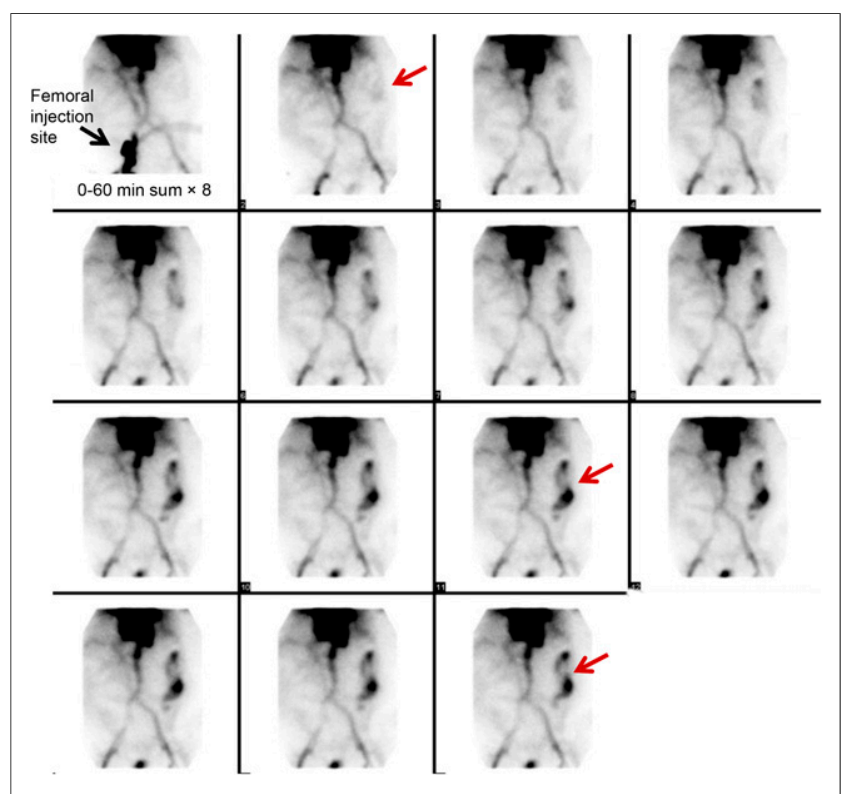

FIGURE 5. Example of bleeding originating from branch of inferior mesenteric artery. Focus of increasing intensity is identified in left upper quadrant and shows anterograde movement. Given its distribution in periphery of abdomen (arrows), focus is typical of large-bowel bleed originating in descending colon. 
if it is suspected on the basis of abdominal or pelvic GIBS. In patients who are being treated with exogenous thyroid hormone or who received prior treatment with ${ }^{131}$ I-sodium iodide or thyroid suppression, the thyroid may not be visualized despite the presence of free pertechnetate. Similarly, salivary activity can be reduced by a host of medical conditions, medications, or prior therapies (e.g., Sjögren syndrome, Parkinson disease, antihistamines, diuretics, antipsychotics, chemotherapy, prior surgical disruption, external-beam radiation therapy, and ${ }^{131}$ I-sodium iodide therapy). Areas of free pertechnetate seen on scintigraphic images include the stomach, salivary glands, thyroid gland, and choroid plexus (29). A lateral image of the pelvis can be helpful to exclude the presence of a rectal bleed and clarify what may be only physiologic penile activity.

\section{SPECT AND SPECT/CT}

In addition to clarifying unclear sites of radiolabeled erythrocytes, SPECT or SPECT/CT has been applied to further define the location of the bleeding - useful in therapeutic planning, particularly angiography or surgery. When this technique is used regularly, dynamic images are generally performed for 10- to 15-min intervals and checked. When a suggestive focus of labeled erythrocytes is identified, SPECT or SPECT/CT can be performed (30). The SPECT/CT scan can be shortened to a 15-min acquisition to arrive at a more rapid diagnosis (7). SPECT/CT has also been found helpful in bleeding sites that are difficult to localize (31-35). In particular, investigators have found that SPECT or SPECT/CT can increase the sensitivity and specificity of bleeding-site localization (30). Accurate localization can help to streamline therapy and achieve an earlier therapeutic response. In the event of rapid intraluminal gastrointestinal bleeding during the SPECT/CT examination, localization might be impaired. Referencing the SNMMI procedure guideline for SPECT/CT imaging is recommended (36).

\section{SENSITIVITY OF GIBS}

GIBS will detect a bleeding rate of $0.05-0.2 \mathrm{~mL} / \mathrm{min}(3,37)$. The sensitivity of GIBS has been reported to be $93 \%$ and the specificity $95 \%(16,17)$, although some investigators have cited lower rates $(38,39)$. The variation in sensitivity is likely related to the lack of a gold standard, but detection rates clearly increase when the study is performed as intended-when the patient is actively bleeding.

There is research indicating which characteristics of positive GIBS can be predictive of positivity on a subsequent angiographic examination. Mehta et al. found that positive GIBS within $12 \mathrm{~min}$ of scanning correlated with a positive angiogram (40). Chamarthy et al. found that visualization of bleeding early, within the first frame of imaging, correlated best with a positive angiogram (41). Prompt performance of GIBS, early time to positivity on GIBS, relative intensity of activity, and prompt performance of angiography subsequent to GIBS were found to lead to a positive angiogram by Lee et al. (42). $\mathrm{Ng}$ et al. found that "immediate" visualization of bleeding on GIBS, defined as 2 min or less, was associated with a positive angiogram (43). In addition, Gupta et al. found that grading the intensity of bleeding may be helpful in predicting angiographic positivity (44). To provide a patient with the best of care, timely evaluation by angiography is important after obtaining GIBS results positive for a gastrointestinal bleed.

\section{GIBS FOR SURGICAL PLANNING}

Several articles have evaluated GIBS in the setting of surgical planning. The opinions are mixed: some reported GIBS to be effective as the sole means for surgical planning $(45,46)$, others suggested that it is useful only as a screening tool before angiography (47), and still others called it "useless" for surgical planning (48). Given this disagreement, it is uncertain how well GIBS performs for surgical planning in all centers. None of these papers evaluated surgical planning with GIBS SPECT/CT, which enhances localization, sensitivity, and specificity. This could be a topic for further investigation.

\section{CT ANGIOGRAPHY (CTA) VERSUS GIBS}

Some centers are starting to move away from GIBS and toward CTA for evaluation of active gastrointestinal bleeding. In CTA, 3 discrete CT scans of the abdomen and pelvis are generally acquired: unenhanced phase (some institutions do not obtain this phase), contrast-enhanced arterial-phase, and delayed-phase. Water and hyperdense oral contrast agent are avoided. The CT slices are quite thin, on the order of 1-2 $\mathrm{mm}$ (49). When referencing appropriateness criteria for lower gastrointestinal bleeding, both GIBS and CTA are ranked similarly according to the American College of Radiology (50).

Although there is controversy about whether GIBS or CTA is best, many have attributed the rapid adoption of CTA to several factors, including faster diagnosis in patients who are clinically deteriorating (51), ability to delineate congenital and other vascular abnormalities that could affect the angiographic approach (52), greater diagnostic accuracy (53), and a relatively similar reported sensitivity of $0.3-1 \mathrm{~mL}$ of extravasated blood (54). Some drawbacks include higher cost and limited time of evaluation (55). Although the Appropriateness Criteria of the American College of Radiology rate the relative radiation level of absorbed dose to the patient as the same for GIBS and CTA, the radiation dose to the patient is higher with CTA (Table 4) (56). The iodinated contrast load is also greater (there is no nephrotoxic aspect to GIBS), although with greater localization less contrast agent might be used on a more selective angiographic evaluation or intervention.

TABLE 4

Comparison of Whole-Body Absorbed Radiation Dose Evaluated by GIBS vs. CTA $(56,72)$

\begin{tabular}{|c|c|}
\hline Technique & Dose (mSv) \\
\hline Pediatric GIBS with $80-784 \mathrm{MBq}$ of $99 \mathrm{~m} T c-$ labeled red blood cells & $0.559-5.488$ \\
\hline Adult GIBS with $555-1,110 \mathrm{MBq}$ of $99 \mathrm{~m}$ Tc-labeled red blood cells & $3.885-7.77$ \\
\hline CTA protocoled for gastrointestinal bleeding without initial unenhanced CT phase & $18.2-28^{*}$ \\
\hline CTA protocoled for gastrointestinal bleeding with initial unenhanced CT phase & $26.8-42^{*}$ \\
\hline
\end{tabular}

*Iterative reconstruction CT will be lower. 
TABLE 5

Pharmaceuticals that Augment Visualization of Meckel Diverticulum $(11,58)$

\begin{tabular}{|c|c|c|}
\hline Pharmaceutical & Dosing/timing & Effect \\
\hline $\begin{array}{l}\text { Cimetidine (other } \mathrm{H}_{2} \text { blockers, such as } \\
\text { famotidine, ranitidine, or proton pump } \\
\text { inhibitors, can also be used but have } \\
\text { different dosing) }\end{array}$ & $\begin{array}{c}20 \mathrm{mg} / \mathrm{kg} / \mathrm{d} \text { orally for } 2 \mathrm{~d} \text { in children or } \\
10-20 \mathrm{mg} / \mathrm{kg} / \mathrm{d} \text { for } 2 \mathrm{~d} \text { in neonates }\end{array}$ & $\begin{array}{l}\text { Inhibits release of } 99 \mathrm{~m} \text { Tc-pertechnetate } \\
\text { by intraluminal cells, thus increasing } \\
\text { and prolonging uptake }\end{array}$ \\
\hline Glucagon & $\begin{array}{l}50 \mu \mathrm{g} / \mathrm{kg} \text { intravenously } 10 \mathrm{~min} \text { after } \\
\text { administration of }{ }^{99 \mathrm{~m} T c-p e r t e c h n e t a t e}\end{array}$ & $\begin{array}{l}\text { Slightly reduces gastric activity of }{ }^{99 \mathrm{~m} T c} \text { - } \\
\text { pertechnetate and suppresses } \\
\text { peristaltic activity }\end{array}$ \\
\hline $\begin{array}{l}\text { Pentagastrin (no longer recommended in } \\
\text { United States secondary to side } \\
\text { effects) }\end{array}$ & $\begin{array}{l}6 \mu \mathrm{g} / \mathrm{kg} \text { subcutaneously } 20-30 \mathrm{~min} \\
\text { before } 99 \mathrm{~m} \text { Tc-pertechnetate } \\
\text { administration }\end{array}$ & $\begin{array}{l}\text { Increases gastric mucosal uptake of } \\
99 \mathrm{~m} \text { Tc-pertechnetate, thus increasing } \\
\text { target-to-background ratio }\end{array}$ \\
\hline
\end{tabular}

Both false-positives and false-negatives can be seen in the setting of GIBS and CTA $(7,57)$.

\section{PEDIATRIC GIBS}

Upper gastrointestinal bleeding has several different etiologies that vary by location of bleeding and age of patient: in newborns to 1-mo-olds, it can be related to milk protein sensitivity, coagulopathy, stress gastritis or ulcer, vitamin $\mathrm{K}$ deficiency, swallowed maternal blood, or vascular anomaly; in 1- to 2-mo-olds, to stress gastritis or ulcer, acid-peptic disease, gastrointestinal duplications, gastric or esophageal varices, duodenal or gastric webs, bowel obstruction, or vascular anomaly; and in children older than 2 mo and adolescents, to acid-peptic disease, caustic ingestion, bowel obstruction, Crohn disease, Dieulafoy lesions, or Mallory-Weiss tears (58).

Lower gastrointestinal bleeding also has different etiologies by age. In newborns to 1-mo-olds, it can be related to necrotizing enterocolitis, allergic proctocolitis, Hirschsprung disease, hemorrhagic disease, or malrotation with volvulus; in 1- to 2-mo-olds, to anal fissure, infectious colitis, allergic proctocolitis, Meckel diverticulum, Hirschsprung disease, intestinal duplication, lymphonodular hyperplasia, and intussusception; in 2- to 5-y-olds, to anal fissures, infectious colitis, polyps, Meckel diverticulum, Henoch-Schönlein purpura, hemolytic uremic syndrome, or lymphonodular hyperplasia; and in children older than $5 \mathrm{y}$, to anal fissures, infectious colitis, polyps, inflammatory bowel disease, and Henoch-Schönlein purpura (58).

The recommended administered activity is based on the European Association of Nuclear Medicine pediatric dosage card, which uses a baseline activity of $56 \mathrm{MBq}$ multiplied by a weight-based factor and a minimum administered activity of $80 \mathrm{MBq}(7,59)$. The imaging technique otherwise generally follows that for adults.

GIBS is preferred in the pediatric population because of the lower absorbed radiation dose, and CTA should be avoided (60). If SPECT/CT is used, the milliampere-seconds settings should be appropriate for patient size and age (34).

\section{MECKEL DIVERTICULUM IMAGING}

In 1809, Johan Friedrick Meckel first comprehensively described the diverticulum that was subsequently to be named for him (26). Bleeding from a Meckel diverticulum can potentially occur at any age but is far more common in children. We recall the "rule of $2 \mathrm{~s}$ " for Meckel diverticulum: 2 feet from the end of the small intestine, 2 inches in length, $2 \%$ of the population, 2 times more common in males, and presenting in the first 2 decades of life and often within the first 2 years. The most common congenital cause of a Meckel diverticulum is failed closure of the omphalomesenteric duct, most commonly in the distal ileum. Approximately $10 \%-60 \%$ of these diverticula contain ectopic mucosa: most commonly gastric but also pancreatic or duodenal (61). Irritation from the gastric acid and pepsin produced in an ectopic location will lead to bleeding (62). Other lesions with ectopic mucosa can include enteric duplications, gastrogenic cysts, and duplication cysts (63).

In preparation for the examination, the patient should fast for $3-4 \mathrm{~h}$ for best sensitivity, although this is not required (64). ${ }^{99 \mathrm{~m}} \mathrm{Tc}-$ pertechnetate is the radiopharmaceutical of choice as it localizes to gastric mucosa. This agent's mechanism of localization is via both the parietal cells and the mucin-secreting cells of the gastric mucosa (11). A Meckel scan assists in localizing the abnormal tissue in preparation for surgical removal. Per the North American Consensus Guidelines for pediatric radiopharmaceutical administered doses, the dosing of ${ }^{99 \mathrm{~m}} \mathrm{Tc}$-pertechnetate is recommended at $1.85 \mathrm{MBq} / \mathrm{kg}$, with a minimum of $9.25 \mathrm{MBq}(65)$. There are a few cold pharmaceuticals that can be used to enhance visualization of a Meckel diverticulum (Table 5) (11,61).

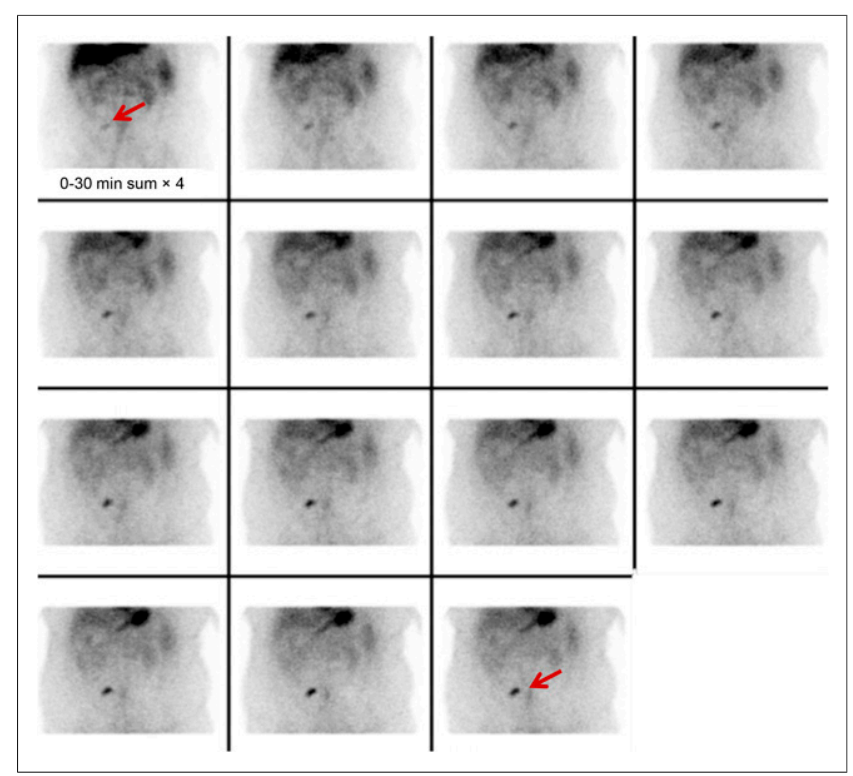

FIGURE 6. Typical imaging appearance of Meckel diverticulum. Focus (arrows) increases in intensity over time, similar to level of gastric uptake. 
TABLE 6

False-Positive Results on Meckel Scanning $(11,58)$

\begin{tabular}{|c|c|}
\hline Related to gastrointestinal tract & Not related to gastrointestinal tract \\
\hline Peptic ulcer & Hydronephrosis \\
\hline Barrett esophagus & Aneurysm of abdominal vessel \\
\hline Retained gastric antrum & Calyceal diverticulum \\
\hline Duplication cyst of ileum & Anterior sacral meningomyelocele \\
\hline Small-bowel obstruction & Hemangioma \\
\hline Appendicitis & Lymphoma \\
\hline Intussusception & Ectopic kidney \\
\hline $\begin{array}{l}\text { Inflammatory bowel diseases (e.g., Crohn } \\
\text { disease or ulcerative colitis) }\end{array}$ & $\begin{array}{l}\text { Recent laparoscopic surgery (hyperemia at periumbilical } \\
\text { port site) }\end{array}$ \\
\hline \multicolumn{2}{|l|}{ Carcinoid of small bowel } \\
\hline \multicolumn{2}{|l|}{ Volvulus } \\
\hline Small-bowel bleeding not related to Meckel diverticulum & \\
\hline
\end{tabular}

Images are acquired dynamically at a frame rate of 30-60 s with a $128^{2}$ matrix, lasting for a minimum of $30 \mathrm{~min}$. Imaging for 60 min can be performed when clinical suspicion is high and the initial 30-min images are negative (61). Postvoiding images or a urinary catheter can be helpful should the diverticulum be obscured by excreted activity in the urinary bladder. A dose of furosemide ( $1 \mathrm{mg} / \mathrm{kg}$ intravenously) may assist in clearing a prominent renal collecting system or ureter (61).

On imaging, a Meckel diverticulum is identified as a focus of activity in the lower abdomen or upper pelvis that generally appears at the time of stomach visualization and increases as stomach activity increases (Fig. 6) (11,20). False-positive results can occur from intussusception, volvulus, abscess, appendicitis, neoplasm, angiodysplasia, Crohn disease, ulcerative colitis, or other forms of colitis (66-70). Table 6 provides more information on gastrointestinal and nongastrointestinal causes of false-positive results on Meckel scans.

SPECT/CT has been described as a troubleshooting technique in Meckel diverticulum, excluding artifacts and assisting in surgical planning (71). Once again, SPECT/CT should be performed with a CT amperage appropriate for patient size and age $(34,61)$.

\section{CONCLUSION}

Scintigraphic imaging of gastrointestinal bleeding remains important in nuclear medicine. The current techniques and interventions have been described in this review. Because gastrointestinal bleeding can be lethal in certain instances, prompt evaluation and direction of care is important. Nuclear medicine can contribute significantly to patient management.

\section{REFERENCES}

1. Alavi A, Dann RW, Baum S, et al. Scintigraphic detection of acute gastrointestinal bleeding. Radiology. 1977;124:753-756.

2. Miskowiak J, Munch O, Nielsen SL, et al. Abdominal scintiphotography with $99 \mathrm{~m}_{\text {technetium-labeled albumin in acute gastrointestinal bleeding: an experimental }}$ study and a case-report. Lancet. 1977;2:852-854.

3. Winzelberg GG, McKusick KA, Strauss HW, et al. Evaluation of gastrointestinal bleeding by red blood cells labeled in vivo with technetium-99m. J Nucl Med. 1979;20:1080-1086.

4. Jairath V, Hearnshaw S, Brunskill SJ, et al. Red cell transfusion for the management of upper gastrointestinal haemorrhage. Cochrane Database Syst Rev. 2010;9:CD006613.
5. El-Tawil AM. Trends on gastrointestinal bleeding and mortality: where are we standing? World J Gastroenterol. 2012;18:1154-1158.

6. Navuluri R, Kang L, Patel J, et al. Acute lower gastrointestinal bleeding. Semin Intervent Radiol. 2012;29:178-186.

7. Dam HQ, Brandon DC, Graham VV, et al. The SNMMI procedure standard/ EANM practice guideline for gastrointestinal bleeding scintigraphy 2.0. J Nucl Med Technol. 2014;42:308-317.

8. Kim BSM, Li BT, Engel A, et al. Diagnosis of gastrointestinal bleeding: a practical guide for clinicians. World J Gastrointest Pathophysiol. 2014;5:467-478.

9. Drug-radiopharmaceutical drug interactions. University of Arkansas for Medical Sciences website. http://nuclearpharmacy.uams.edu/resources/Interactions. htm. Accessed December 14, 2015.

10. Braga AC, Oliveria MB, Feliciano GD, et al. The effects of drugs on the labeling of blood elements with technetium-99m. Curr Pharm Des. 2000;6:1179-1191.

11. Ziessman H, O'Malley J, Thrall J. Nuclear Medicine: The Requisites. 4th ed. Philadelphia, PA: Elsevier Saunders; 2013:307-321.

12. Vidal MV, Gutfilen B, da Fonseca LM, et al. Influence of tobacco on the labeling of red blood cells and plasma proteins with technetium-99m. J Exp Clin Cancer Res. 1998;17:41-46.

13. Bustani H, Colavolpe C, Imbert-Joscht I, et al. Chocolate intake associated with failed labeling of ${ }^{99 \mathrm{~m}} \mathrm{Tc}$ red blood cells. J Nucl Med Technol. 2009;37:107-110.

14. Kawabe J, Higashiyama S, Torli K, et al. Poor labeling of Tc-99m red blood cells in vivo in a radionuclide intestinal bleeding study of a patient who had recently undergone frequent blood transfusions. Clin Nucl Med. 2003;28:911-912.

15. Sampson CB. Complications and difficulties in radiolabelling blood cells: a review. Nucl Med Commun. 1996;17:648-658.

16. Siddiqui AR, Schauwecker DS, Wellman HN, et al. Comparison of technetium- $99 \mathrm{~m}$ sulfur colloid and in vitro labeled technetium-99m RBCs in the detection of gastrointestinal bleeding. Clin Nucl Med. 1985;10:546-549.

17. Bunker SR, Lull RJ, Tanasescu DE, et al. Scintigraphy of gastrointestinal hemorrhage: superiority of Tc-99m red blood cells over Tc-99m sulfur colloid. AJR. 1984;143:543-548.

18. Bunker SR, Brown JM, McAuley RJ, et al. Detection of gastrointestinal bleeding sites: use of in vitro technetium Tc99m-labeled RBCs. JAMA. 1982;247:789-792.

19. Kotani K, Kawabe J, Higashiyama S, et al. Diagnostic ability of ${ }^{99 m}$ Tc-HASDTPA scintigraphy in combination with SPECT/CT for gastrointestinal bleeding. Abdom Imaging. 2014;39:677-684.

20. Henkin RE, Bova D, Dillehay GL, et al. Nuclear Medicine. 2nd ed. Philadelphia, PA: Mosby Elsevier. 2006:988-993.

21. Ultratag RBC package insert. Mallinckrodt website. http://www2.mallinckrodt. com/WorkArea/DownloadAsset.aspx?id=654. Published October 2015. Accessed December 11, 2015.

22. Maurer AH. Gastrointestinal bleeding and cine-scintigraphy. Semin Nucl Med. 1996;26:43-50.

23. Winzelberg GG, Froelich JW, McKusick KA, et al. Radionuclide localization of lower gastrointestinal hemorrhage. Radiology. 1981;139:465-469.

24. Markisz JA, Front D, Royal HD, et al. An evaluation of Tc-99m-labeled red blood cell scintigraphy for the detection and localization of gastrointestinal bleeding sites. Gastroenterology. 1982;83:394-398. 
25. Netter FH. Atlas of Human Anatomy. 6th ed. Philadelphia, PA: Saunders; 2014: 259-271.

26. Lewis DH, Jacobson AF. BUN/Cr ratios: aid to decision making about delayed imaging in Tc-99m red blood cell scans for gastrointestinal hemorrhage. Clin Nucl Med. 1998;23:201-204.

27. Jacobson AF. Cerqueria: prognostic significance of late imaging results in technetium-99m-labeled red blood cell gastrointestinal bleeding studies with early negative images. J Nucl Med. 1992;33:202-207.

28. Howarth DM. The role of nuclear medicine in the detection of acute gastrointestinal bleeding. Semin Nucl Med. 2006;36:133-146.

29. Stern SS, Leslie WD, Dupont JO, et al. Hepatobiliary clearance of intravenous Tc-99m pertechnetate. Clin Nucl Med. 1995;20:962-964.

30. Dolezal J, Vizda J, Kopacova M. Single-photon emission computed tomography enhanced Tc-99m-pertechnetate disodium-labeled red blood cell scintigraphy in the localization of small intestine bleeding: a single-centre twelve-year study. Digestion. 2011;84:207-211.

31. Bentley BS, Tulchinsky M. SPECT/CT helps in localization and guiding management of small bowel gastrointestinal hemorrhage. Clin Nucl Med. 2014;39: 94-96.

32. Schillaci O, Spanu A, Tagliabue L, et al. SPECT/CT with a hybrid imaging system in the study of lower gastrointestinal bleeding with technetium-99m red blood cells. Q J Nucl Med Mol Imaging. 2009;53:281-289.

33. Schillaci O, Filippi L, Danieli R, et al. Single-photon emission computed tomography/computed tomography in abdominal diseases. Semin Nucl Med. 2007;37:48-61.

34. Schillaci O, Danieli R, Manni C, et al. Is SPECT/CT with a hybrid camera useful to improve scintigraphic imaging interpretation? Nucl Med Commun. 2004;25: 705-710.

35. Yama N, Ezoe E, Kimura Y, et al. Localization of intestinal bleeding using a fusion of Tc-99m-labeled RBC SPECT and x-ray CT. Clin Nucl Med. 2005;30: 488-489.

36. Delbeke D, Coleman RE, Guiberteau MJ, et al. Procedure guideline for SPECT/CT imaging 1.0. J Nucl Med. 2006;47:1227-1234.

37. Zuckerman DA, Bocchini TP, Birnbaum EH. Massive hemorrhage in the lower gastrointestinal tract in adults: diagnostic imaging and intervention. AJR. 1993;161: 703-711.

38. Pennoyer WP, Vignati PV, Cohen JL. Mesenteric angiography for lower gastrointestinal hemorrhage: are there any predictors for a positive study? Dis Colon Rectum. 1997;40:1014-1018.

39. Gunderman R, Leef J, Ong K, et al. Scintigraphic screening prior to visceral arteriography in acute lower gastrointestinal bleeding. J Nucl Med. 1998;39: 1081-1083.

40. Mehta AS, Amin A, Masse N, et al. Predicting positive angiograms by ${ }^{99 \mathrm{~m}} \mathrm{Tc}-\mathrm{red}$ blood cell (RBC) scintigraphy in patients with lower GI hemorrhage: time to positivity. JVIR. 2015;26(suppl):S102.

41. Chamarthy M, Shapoval A, Golowa Y, et al. Utility of positive nuclear gastrointestinal bleeding imaging parameters to predict subsequent successful angiographic localization. JVIR. 2011;22(suppl):S31.

42. Lee JH, Rashid S, Hargreaves EL, et al. Differentiating variables that predict positive angiograms in gastrointestinal hemorrhage. JVIR. 2013;24(suppl):S137.

43. Ng DA, Opelka FG, Beck DE, et al. Predictive value of technetium Tc 99mlabeled red blood cell scintigraphy for positive angiogram in massive lower gastrointestinal hemorrhage. Dis Colon Rectum. 1997;40:471-477.

44. Gupta SM, Spencer RP, Chak SP. Significance of intensity of delayed activity during technetium-99m-RBC gastrointestinal bleeding study. J Nucl Med. 1991;32: 2249-2252.

45. Alavi A, Ring EJ. Localization of gastrointestinal bleeding: superiority of ${ }^{99 \mathrm{~m}} \mathrm{Tc}$ sulfur colloid compared with angiography. AJR. 1981;137:741-748.

46. Dusold R, Burke K, Carpentier W, et al. The accuracy of technetium-99mlabeled red cell scintigraphy in localizing gastrointestinal bleeding. Am J Gastroenterol. 1994;89:345-348.

47. Hunter JM, Pezim ME. Limited value of technetium 99m-labeled red cell scintigraphy in localization of lower gastrointestinal bleeding. Am J Surg. 1990;159: 504-506.
48. Miller TA. Tagged red blood cell imaging to localize gastrointestinal bleeding: is it really that helpful? Gastroenterology. 1992;102:733.

49. Jaeckle T, Stuber G, Hoffman HK, et al. Acute gastrointestinal bleeding: value of MDCT. Abdom Imaging. 2008;33:285-293.

50. ACR appropriateness criteria: radiologic management of lower gastrointestinal tract bleeding. American College of Radiology website. https://acsearch.acr.org/ docs/69457/Narrative/. Published 2006. Updated 2014. Accessed December 11, 2015.

51. Geffroy Y, Rodallec MH, Boulay-Coletta I, et al. Multidetector CT angiography in acute gastrointestinal bleeding: why, when and how. Radiographics. 2011;31: E35-E46.

52. Zink SI, Ohki SK, Stein B, et al. Noninvasive evaluation of active lower gastrointestinal bleeding: comparison between contrast enhanced MDCT and ${ }^{99 \mathrm{~m}} \mathrm{Tc}-$ labeled RBC scintigraphy. AJR. 2008;191:1107-1114.

53. Jacovides CL, Nadolski G, Allen SR, et al. Arteriography for lower gastrointestinal hemorrhage role of preceding abdominal computed tomographic angiogram in diagnosis and localization. JAMA Surg. 2015;150:650-656.

54. Kuhle WG, Shelman RG. Detection of active colonic hemorrhage with use of helical CT: findings in a swine model. Radiology. 2003;228:743-752.

55. Laing CJ, Tobias T, Rosenblum DI, et al. Acute gastrointestinal bleeding: emerging role of multidetector CT angiography and review of current imaging techniques. Radiographics. 2007;27:1055-1070.

56. RADAR medical procedure radiation dose calculator and consent language generator. The RAdiation Dose Assessment Resource website. http://www.doseinforadar.com/RADARDoseRiskCalc.html. Accessed December 11, 2015.

57. Stuber T, Hoffman MHK, Stuber G, et al. Pitfalls in detection of acute gastrointestinal bleeding with multi-detector row helical CT. Abdom Imaging. 2009;34: 476-482.

58. Treves ST. Pediatric Nuclear Medicine/PET. 3rd ed. New York, NY: Springer; 2007:192-208.

59. Dosage card (version 1.2.2014). European Association of Nuclear Medicine website. http://www.eanm.org/docs/EANM_Dosage_Card_040214.pdf? PHPSESSID $=$ nb6bln4nl6sdts2632a5qrop60. Accessed December, 2015.

60. Fahey FH, Treves ST, Adelstein SJ. Minimizing and communicating radiation risk in pediatric nuclear medicine. J Nucl Med Technol. 2012;40:13-24.

61. Turgeon DK, Bennet JL. Meckel's diverticulum. Am J Gastroenterol. 1990;85: 777-781.

62. Brayton D. Gastrointestinal bleeding of unknown origin. Am J Dis Child. 1964;107: 288-292.

63. Kong MS, Huang SC, Tzen KY, Lin JN. Repeated technetium-99m pertechnetate scanning for children with obscure gastrointestinal bleeding. J Pediatr Gastroenterol Nutr: 1994;18:284-287.

64. Spottswood SE, Pfluger T, Bartold SP, et al. SNMMI and EANM practice guideline for Meckel diverticulum scintigraphy 2.0. J Nucl Med Technol. 2014;42: $163-169$.

65. Gelfand MJ, Parisi MT, Treves ST, et al. Pediatric radiopharmaceutical administered doses: 2010 North American consensus guidelines. J Nucl Med. 2011;52: 318-322.

66. Lunia S, Lunia C, Chandramouly B, Chodos RB. Radionuclide meckelogram with particular reference to false-positive results. Clin Nucl Med. 1979;4:285-288.

67. Tulchinsky M. Meckel's scan: pitfall in patients with active small bowel bleeding. Clin Nucl Med. 2006;31:814-816.

68. McKevitt EC, Baerg JE, Nadel HR, et al. Laparoscopy as a cause of a falsepositive Meckel's scan. Clin Nucl Med. 1999;24:102-104.

69. Blackmon KN, Rao AG. Ectopic kidney mimicking a Meckel's diverticulum on Tc-99m pertechnetate scan. Clin Nucl Med. 2011;36:e228-e230.

70. Cherng SC, Fan YM, Yu CY, et al. Incidental accumulation of technetium-99m pertechnetate in pediatric Burkitt's lymphoma with tumor-induced intussusception. Clin Nucl Med. 2004;29:264-265.

71. Papathanassiou D, Leihn JC, Meneroux B, et al. SPECT-CT of Meckel diverticulum. Clin Nucl Med. 2007;32:218-220.

72. Kulkarni C, Moorthy S, Sreekumar K, et al. In the workup of patients with obscure gastrointestinal bleed, does 64-slice MDCT have a role? Indian J Radiol Imaging. 2012;22:47-53. 